\title{
Decreased Linezolid Serum Concentrations in Three Critically III Patients: Clinical Case Studies of a Potential Drug Interaction between Linezolid and Rifampicin
}

\author{
Ute Blassmann $^{\mathrm{a}} \quad$ Anka C. Roehr ${ }^{\mathrm{b}}$ Otto R. Frey ${ }^{\mathrm{b}}$ Andreas Koeberer ${ }^{\mathrm{c}}$ \\ Josef Briegel ${ }^{d}$ Volker Huge ${ }^{d}$ Cornelia Vetter-Kerkhoffa \\ ${ }^{a}$ Apotheke, Klinikum der Universität München, München, ${ }^{b}$ Apotheke, Kliniken Landkreis Heidenheim gGmbH, \\ Heidenheim, ' ${ }^{C}$ linik für Anästhesiologie, Operative Intensivmedizin und Spezielle Schmerztherapie, Kliniken \\ Landkreis Heidenheim gGmbH, Heidenheim, ${ }^{d}$ Klinik für Anaesthesiologie, Klinikum der Universität München, \\ München, Germany
}

\section{Key Words}

Rifampicin · Linezolid · Drug monitoring · Drug

interactions · Anti-bacterial agents · Pharmacokinetics

\begin{abstract}
Linezolid is a valuable treatment option for treating infections caused by multi-resistant gram-positive pathogens. Lack of effective linezolid levels due to the co-administration of rifampicin has been described in healthy subjects. However, the clinical significance of this potential drug interaction (DI) for critically ill patients is still unclear. This was a retrospective analysis of 3 critically ill patients with the combination therapy of linezolid and rifampicin or rifampicin pre-treatment. Despite increasing the dose of linezolid, the majority of observed linezolid trough concentrations in all 3 patients were below $2 \mathrm{mg} / \mathrm{l}$. Furthermore, linezolid trough concentrations remained below $2 \mathrm{mg} / \mathrm{l}$ after discontinuation of rifampicin. This potential DI between linezolid and rifampicin could lead to treatment failure. Therefore, we strongly recommend that linezolid serum concentrations be monitored in patients with rifampicin co-administration or rifampicin pretreatment.

(c) 2016 S. Karger AG, Basel
\end{abstract}

\section{Introduction}

Infections caused by multi-resistant gram-positive pathogens represent a major burden on healthcare. If risk factors for methicillin-resistant staphylococcus aureus (MRSA) are present, vancomycin is indicated [1]. Especially for implant-associated infections (e.g. infections of total endoprothesis, prosthetic valve endocarditis), the combination therapy with rifampicin and vancomycin is recommended [1]. However, linezolid is often used in case of resistance or contraindication to vancomycin or if sequential therapy is indicated [1]. Due to the long-lasting treatment duration of implant-associated infections, the high oral bioavailability of linezolid (approximately $100 \%$ ) [2] is an attractive oral alternative to intravenous glycopeptides.

Pharmacodynamic kill characteristics of linezolid are concentration-dependent with time-dependence. Therefore, AUC/MIC $>100$ (where, AUC = area under the antibiotic concentration-time curve for $24 \mathrm{~h}, \mathrm{MIC}=$ minimal inhibitory concentration) is proposed as pharmacokinetic index predictive for efficacy [3]. Due to the MIC values of pathogens, trough concentrations $\geq 2 \mathrm{mg} / \mathrm{l}$ and/

\section{KARGER}

E-Mail karger@karger.com

www.karger.com/pha
(C) 2016 S. Karger AG, Basel

0031-7012/16/0982-0051\$39.50/0
Ute Blassmann

Klinikum der Universität München

Apotheke Marchioninistr. 15

DE-81377 München (Germany)

E-Mail Ute.Blassmann@med.uni-muenchen.de 
or $\mathrm{AUC}_{24}>160-200 \mathrm{mg}^{*} \mathrm{~h} / \mathrm{l}$ should be achieved to inhibit the growth of $90 \%$ of organisms (MIC90) for staphylococci [3].

Recently, it has been demonstrated that linezolid plasma exposure might significantly vary in some patient populations [4] and in those receiving polypharmacy [5]. Co-administrations of drugs such as clarithromycin, amiodarone, amlodipine, or omeprazole may be responsible for linezolid overexposure, which could favor drug-related adverse events [5]. In contrast, lack of effective linezolid concentrations due to the co-administration of rifampicin is described in healthy subjects, and this could lead to treatment failure $[2,6]$. However, the clinical significance of this potential drug interaction (DI) for critically ill patients is still unclear.

The objective of this clinical case study was to report about linezolid serum concentrations in critically ill patients with rifampicin co-administration or rifampicin pretreatment.

\section{Methods}

This was a retrospective analysis of critically ill patients who were treated with the combination therapy of linezolid and rifampicin or rifampicin pretreatment due to suspected or proven MRSA infection and therapeutic drug monitoring (TDM) of linezolid. Ethical approval was obtained from the ethics committees (Ludwig-Maximilian-Universität München, München, Germany; Universität Ulm, Ulm, Germany). The ethics committee waived the need for patient consent due to the retrospective nature of the study. Blood samples were collected just before the initiation of the linezolid infusion (trough in serum, steady-state; $\mathrm{C}_{\text {min }}$, ss) and within half an hour after linezolid infusion at 3 or $4 \mathrm{~h}$ (peak in serum, steady-state; $\mathrm{C}_{\max }$, ss). Linezolid trough and peak concentrations in serum were measured by a validated high-performance liquid chromatography with ultraviolet detection, as has been previously described in detail [7].

\section{Results}

Three critically ill patients with linezolid and rifampicin co-administration or rifampicin pretreatment were analyzed. In total, 22 blood samples were collected.

\section{Case 1}

A 65 -year-old patient (weight $65 \mathrm{~kg}$, height $165 \mathrm{~cm}$ ) with a history of bowel syndrome and pulmonary emphysema was hospitalized because of subarachnoid hemorrhage with concomitant obstructive hydrocephalus. The patient underwent successful clipping of a posterior infe- rior cerebellar artery aneurysm, and an intraventricular catheter (IVC) was placed for the management of hydrocephalus. Treatment with ceftriaxone and clindamycin was initiated because of aspiration pneumonia and bone infection prophylaxis for 7 days. On day 7, the patient developed an IVC-associated ventriculitis. The IVC was replaced and empirical antibiotic therapy was commenced with vancomycin (2 times daily, targeting serum trough concentration of $15-20 \mathrm{mg} / \mathrm{ml})$ and meropenem $(2 \mathrm{~g}$ 3 times daily). No pathogens could be isolated from the cerebrospinal fluid (CSF) sample. On day 9, a combination therapy with rifampicin (600 $\mathrm{mg}$ once a day) for 7 days was commenced because of a deteriorating condition. On day 15, vancomycin was withdrawn because of an increase in serum creatinine levels (from 0.8 to $1.4 \mathrm{mg} / \mathrm{l}$ ) and replaced by linezolid (600 mg 2 times daily). Rifampicin was replaced by fosfomycin ( 5 g 3 times daily) because of persisting inflammatory response and high cell count in the CSF. In addition, aspiration pneumonia was treated with moxifloxacin (400 mg once a day) for 7 days because of progressive pulmonary infiltrates. On day 16, the patient developed acute kidney injury probably due to $\mathrm{X}$-ray contrast medium and was treated with continuous veno-venous hemodialysis for 6 days (dialysate flow 2,000 $\mathrm{ml}$, blood flow $100 \mathrm{ml}$ ). TDM of linezolid was started. On days 17 and 19, serum trough concentrations of linezolid were undetectable $(<0.5 \mathrm{mg} / \mathrm{l})$. Linezolid serum concentrations at $7 \mathrm{~h}$ were $0.5 \mathrm{mg} / \mathrm{l}$ (table 1 ). On day 19, IVCassociated ventriculitis was cured; however, antibiotic therapy was continued until day 27 as recommended in guidelines. On days 21, 26 and 27, serum trough concentrations of linezolid remained below $2.2 \mathrm{mg} / \mathrm{l}$ (table 1 ). Serum peak concentrations of linezolid increased but remained below $10 \mathrm{mg} / \mathrm{l}$. The IVC was removed on day 35 . The patient was discharged from the hospital for further rehabilitation on day 44 (table 1; fig. 1).

\section{Case 2}

A 72-year-old patient (weight $90 \mathrm{~kg}$, height $168 \mathrm{~cm}$ ) with a history of coronary heart disease, peripheral arterial disease and kidney disease was hospitalized because of shoulder empyema. The patient underwent humeral head resection. On day 3 of treatment with ciprofloxacin (400 mg 2 times daily), linezolid (600 mg 2 times daily) and rifampicin (600 $\mathrm{mg} 2$ times daily) were initiated due to MRSA growing in the blood cultures after pretreatment with ampicillin/sulbactam. On day 5, ciprofloxacin was stopped due to the results of resistance testing. TDM of linezolid was started. Serum trough concentrations of linezolid were below $1 \mathrm{mg} / \mathrm{l}$ at days 4 , 
Table 1. Linezolid doses and corresponding linezolid serum concentrations in 3 critically ill patients with rifampicin pretreatment (case 1) or rifampicin co-administration (cases 2 and 3 )

\begin{tabular}{|c|c|c|c|c|c|c|}
\hline $\begin{array}{l}\text { Day of linezolid } \\
\text { therapy }\end{array}$ & $\begin{array}{l}\text { Dosage } \\
\text { linezolid, mg }\end{array}$ & $\begin{array}{l}\text { Infusion time } \\
\text { linezolid, h }\end{array}$ & $\begin{array}{l}\text { Co-administration } \\
\text { with rifampicin, mg }\end{array}$ & $\begin{array}{l}\text { Rifampicin } \\
\text { administration }\end{array}$ & $\begin{array}{l}\text { Linezolid Cmin, ss, } \\
(\mathrm{mg} / \mathrm{l})\end{array}$ & $\begin{array}{l}\text { Linezolid Cmax, ss, } \\
(\mathrm{mg} / \mathrm{l})\end{array}$ \\
\hline \multicolumn{7}{|l|}{ Case 1} \\
\hline 5 & $2 \times 600$ & 4 & Day 5 without rifampicin & - & $<0.5$ & 0.5 ( $7 \mathrm{~h}$ after infusion start) \\
\hline 7 & $2 \times 600$ & 4 & Day 7 without rifampicin & - & 2.1 & 3.3 \\
\hline 12 & $2 \times 600$ & 4 & Day 12 without rifampicin & - & 2.0 & 3.9 \\
\hline \multicolumn{7}{|l|}{ Case 2} \\
\hline 2 & $2 \times 600$ & 0.5 & $2 \times 600$ & IV & 0.6 & 8.0 \\
\hline 4 & $3 \times 600$ & 0.5 & $2 \times 600$ & IV & $4.1-1.5 \mathrm{~h}$ too early & 11.7 \\
\hline 8 & $3 \times 600$ & 0.5 & $2 \times 600$ & IV & 0.9 & ND \\
\hline 21 & $3 \times 600$ & Oral & $2 \times 600$ & IV & 0.9 & ND \\
\hline 25 & $3 \times 600$ & Oral & $2 \times 600$ & IV & 0.8 & ND \\
\hline 3 & $3 \times 600$ & 0.5 & $2 \times 300$ & Oral & 0.5 & ND \\
\hline 7 & $3 \times 600$ & Oral & $2 \times 450$ & Oral & 1.9 & 6.5 \\
\hline
\end{tabular}

IV = Intravenous; $\mathrm{ND}=$ not determined.

Fig. 1. Linezolid serum concentrations case 1 as example. Therapeutic serum concentrations of linezolid are expected to be between 4 and $10 \mathrm{mg} / \mathrm{l}$ using standard dosing (600 mg 2 times daily). Due to the MIC values of pathogens, trough concentrations $\geq 2 \mathrm{mg} / \mathrm{l}$ and/or $\mathrm{AUC}_{24}>160-200 \mathrm{mg}^{*} \mathrm{~h} / \mathrm{l}$ should be achieved to inhibit the growth of $90 \%$ of organisms (MIC90) for staphylococci [3]. Linezolid trough concentrations were even below $2 \mathrm{mg} / \mathrm{l} 13$ days after rifampicin discontinuation.

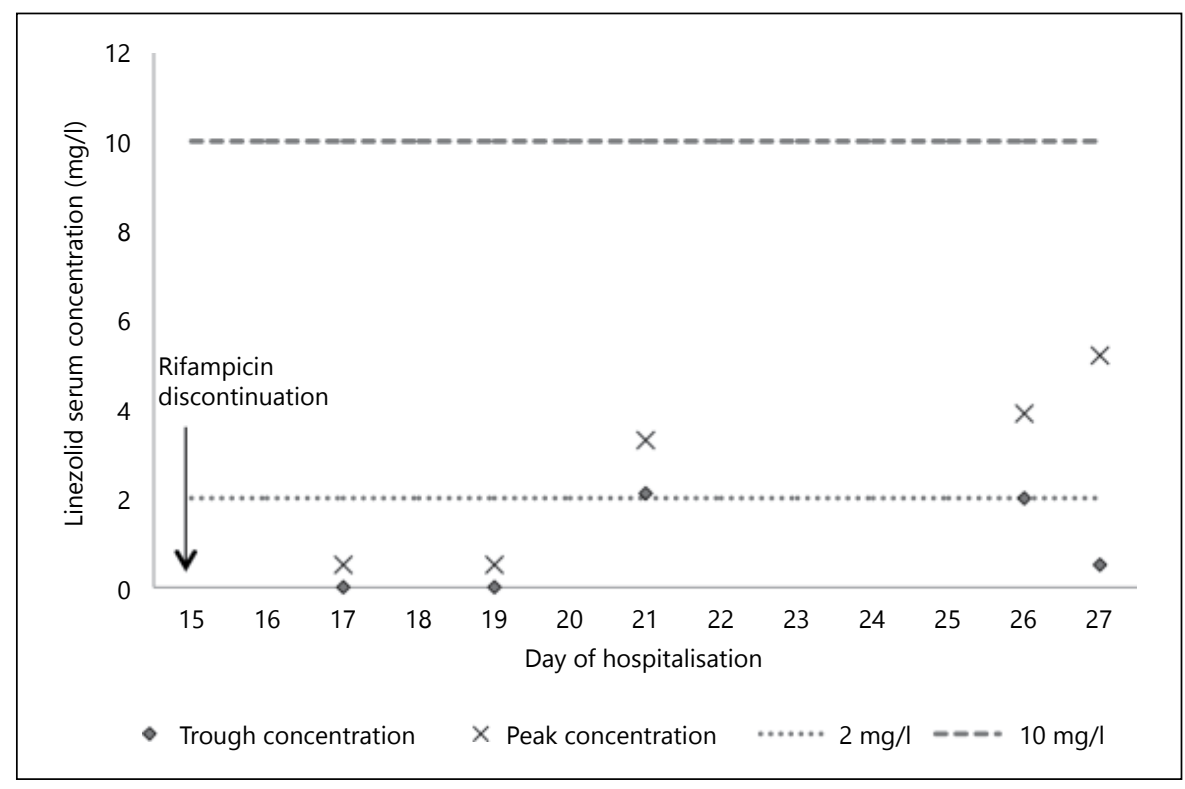

6 and 10 , despite dose increases to $1,800 \mathrm{mg} / 24 \mathrm{~h}$ (table 1). On days 4 and 6 , serum peak concentrations of linezolid were 8.0 and $11.7 \mathrm{mg} / \mathrm{l}$, respectively (table 1). On day 12, intravenous linezolid was switched to oral linezolid $(1,800 \mathrm{mg} / 24 \mathrm{~h})$. Serum trough concentrations of linezolid remained below $1 \mathrm{mg} / \mathrm{l}$ on days 19 and 23 (table 1). On day 24, linezolid was increased to 2,700 $\mathrm{mg} / 24 \mathrm{~h}$. Peak serum concentration of linezolid ( $1 \mathrm{~h}$ after oral administration) was $5 \mathrm{mg} / \mathrm{l}$ (table 1 ). On day 25 , linezolid was discontinued due to microbiological cure 
after knee puncture. Antibiotic therapy was terminated on day 25. The patient was discharged from the hospital on day 26.

\section{Case 3}

A 77-year-old patient (weight $107 \mathrm{~kg}$, height $178 \mathrm{~cm}$ ) with a history of diabetes and heart disease was hospitalized because of total endoprothesis infection after knee anthroplasty surgery. The patient underwent endoprothesis removal and a spacer was placed. Staphylococcus epidermidis was isolated from a knee puncture. Treatment with vancomycin ( $1 \mathrm{~g} 2$ times daily) and rifampicin (600 mg 2 times daily) was initiated. On day 18, vancomycin was switched to linezolid (600 mg 2 times daily). Rifampicin was reduced to $300 \mathrm{mg} 2$ times daily. Linezolid TDM was started. Serum concentrations of linezolid were measured on days 19 and 20. On day 21, linezolid was switched to oral linezolid and increased to $1,800 \mathrm{mg} / 24 \mathrm{~h}$ because of linezolid serum concentrations below $1.0 \mathrm{mg} / \mathrm{l}$ (table 1). On day 25, linezolid serum trough concentration $30 \mathrm{~min}$ before administration and $1 \mathrm{~h}$ after administration were 1.9 and $6.5 \mathrm{mg} / \mathrm{l}$, respectively (table 1 ). On day 25 , rifampicin was increased to $450 \mathrm{mg} 2$ times daily. The patient was discharged from the hospital on day 31 .

\section{Discussion}

In these clinical case studies, we observed an increased linezolid clearance in critically ill patients with rifampicin co-administration as well as rifampicin pretreatment. Although trough serum concentrations of linezolid are supposed to be between 4 and $6 \mathrm{mg} / \mathrm{l}$ [3], the majority of observed trough serum concentrations of linezolid in all 3 patients were below the MIC of susceptible MRSA $(<2 \mathrm{mg} / \mathrm{l})$ [3], despite increasing the dose of linezolid in 2 patients (see Results). Moreover, linezolid trough concentrations were even below $2 \mathrm{mg} / \mathrm{l} 13$ days after rifampicin discontinuation in case 1 (see Results; table 1).

Rifampicin is able to induce several hepatic enzymes like cytochrome 450 enzymes (CYP) as well as carrier proteins like P-glycoprotein (P-gp). Co-administration of rifampicin and other drugs that are transported by P-gp or metabolized by the hepatic CYP system can lead to clinical relevant DI due to the induction of enzymes in shared metabolic pathways. Therefore, rifampicin has a high potential for pharmacokinetic interactions with other drugs [8].

Linezolid is primarily metabolized by the oxidation of the morpholine ring, which results in 2 inactive major metabolites. Urinary elimination accounts for $35 \%$ of the parent drug [9]. However, the enzyme system or oxidants formation in vivo have not been elucidated yet [10]. A discussion on the participation of CYP in the metabolic pathway led to controversial results $[5,9,10,11]$.

Recently, interactions between rifampicin and linezolid have been reported, in which linezolid serum concentrations were reduced $[6,11-13]$. Rifampicin was shown to cause about $30 \%$ reduction of linezolid exposure in healthy subjects $[6,11]$. Yet, in our case study, linezolid trough concentrations are even lower. Zoller et al. [4] described a high variability of linezolid serum concentrations in a heterogeneous group of critically ill patients. One possible reason could be that linezolid serum exposure might significantly vary in some patient populations such as critically ill patients. Indeed, decreased linezolid concentrations by $40-60 \%$ were described in a critically ill patient [12] and decreased linezolid concentrations by $87-94 \%$ in 2 non-critically ill patients [13].

Moreover, several retrospective observational studies described a lower incidence of hematological adverse events among patients receiving rifampicin and linezolid compared to patients receiving linezolid alone. This might indicate clinical significance of this DI. Soriano et al. [14] investigated the effects of rifampicin on hematological adverse events induced by linezolid in a comparative study. The co-administration of rifampicin was associated with a lower risk of thrombocytopenia. Likewise, Legout et al. [15] described a lower risk of anemia in patients with bone and joint infections if they received rifampicin and linezolid compared to patients receiving linezolid alone or in combination with other drugs. On the contrary, differences in clinical success rates were not observed. Pea et al. [5] investigated the toxicity of long-term treatment with linezolid. Patients receiving rifampicin and linezolid vs. receiving linezolid alone had significantly lower trough concentrations $\left(\mathrm{C}_{\min } 1.37\right.$ vs. $\left.3.71 \mathrm{mg} / \mathrm{l}\right)$ or $\mathrm{AUC}_{24}$ (123.33 vs. $\left.212.77 \mathrm{mg}^{*} \mathrm{~h} / \mathrm{l}\right)$. Furthermore, there was a lower risk of thrombocytopenia ( 0 vs. $51.4 \%$ ). Consequently, rifampicin seemed to display a protective effect against hematological toxicity. More important, treatment failure was observed more often in the rifampicinlinezolid group. Therefore, Pea et al. [5] concluded that there is no benefit of the co-administration that justifies the risk of insufficient dosing and therefore potential antibiotic treatment failure of linezolid. However, the clinical significance of this potential interaction has not yet been established and the mechanism needs further research. The mechanism of the pharmacokinetic DI between rifampicin and linezolid could be due to metabo- 
lism induction. Because DI can also be observed after rifampicin pretreatment, induction of protein synthesis would be most plausible, but the mechanism is found to result in controversial outcomes $[6,11]$.

\section{Conclusions}

Our clinical case studies support clinical significance of this potential DI between linezolid and rifampicin for critically ill patients, even if rifampicin is already discontinued. We observed sub-therapeutic linezolid serum concentrations in patients with rifampicin co-administration as well as rifampicin pretreatment. Although decreased linezolid concentrations in healthy subjects are already described in the summary of product characteristics of linezolid [2], recommendations with regard to patient management are not available yet. The decrease in linezolid concentrations could be related to induction of metabolism by rifampicin but the mechanism of this potential DI is still not understood.

Clinicians should be aware of this potential interaction that could lead to antibiotic treatment failure of linezolid. These clinical case studies emphasize the value and need of monitoring linezolid serum concentrations with rifampicin co-administration and pretreatment. Further investigation is needed to assess the clinical significance of the combination therapy.

\section{Disclosure Statement}

The author(s) declare that they have no competing interests.

\section{Acknowledgment}

We thank Yvonne Hopf for critically reviewing the manuscript.

\section{References}

1 Liu C, Bayer A, Cosgrove SE, Daum RS, Fridkin SK, Gorwitz RJ, et al: Clinical practice guidelines by the Infectious Diseases Society of America for the treatment of methicillinresistant Staphylococcus aureus infections in adults and children: executive summary. Clin Infect Dis 2011;52:285-292.

2 Pfizer. Zyvox ${ }^{\circledR}$. www.accessdata.org2015.

3 EUCAST. Linezolid Rationale for the EUCAST clinical breakpoints, version 1.0. www.eucast.org2005.

4 Zoller M, Maier B, Hornuss C, Neugebauer C, Döbbeler G, Nagel D, et al: Variability of linezolid concentrations after standard dosing in critically ill patients: a prospective observational study. Crit Care 2014;18:R148.

5 Pea F, Viale P, Cojutti P, Del Pin B, Zamparini E, Furlanut M: Therapeutic drug monitoring may improve safety outcomes of long-term treatment with linezolid in adult patients. J Antimicrob Chemother 2012;67:2034-2042.

6 Egle H, Trittler R, Kümmerer K, Lemmen SW: Linezolid and rifampin: drug interaction contrary to expectations? Clin Pharmacol Ther 2005;77:451-453.
7 Roehr AC, Frey OR, Koeberer A, Fuchs T, Roberts JA, Brinkmann A: Anti-infective drugs during continuous hemodialysis - using the bench to learn what to do at the bedside. Int J Artif Organs 2015;38:17-22.

8 Mills JB, Rose KA, Sadagopan N, Sahi J, de Morais SM: Induction of drug metabolism enzymes and MDR1 using a novel human hepatocyte cell line. J Pharmacol Exp Ther 2004; 309:303-309.

9 Slatter J, Stalker DJ, Feenstra KL, Welshman IR, Bruss JB, Sams JP, et al: Pharmacokinetics, metabolism, and excretion of linezolid following an oral dose of [(14)C]linezolid to healthy human subjects. Drug Metab Dispos 2001;29:1136-1145.

10 Stalker DJ, Jungbluth GL: Clinical pharmacokinetics of linezolid, a novel oxazolidinone antibacterial. Clin Pharmacokinet 2003;42: 1129-1140.

11 Gandelman K, Zhu T, Fahmi OA, Glue P, Lian K, Obach RS, et al: Unexpected effect of rifampin on the pharmacokinetics of linezolid: in silico and in vitro approaches to explain its mechanism. J Clin Pharmacol 2011;51: 229-236.
12 Gebhart BC, Barker BC, Markewitz BA: Decreased serum linezolid levels in a critically ill patient receiving concomitant linezolid and rifampin. Pharmacotherapy 2007;27:476479.

13 Hoyo I, Martínez-Pastor J, Garcia-Ramiro S, Climent C, Brunet M, Cuesta M, et al: Decreased serum linezolid concentrations in two patients receiving linezolid and rifampicin due to bone infections. Scand J Infect Dis 2012;44:548-550.

14 Soriano A, Ortega M, García S, Peñarroja G, Bové $\mathrm{A}, \mathrm{Marcos} \mathrm{M}$, et al: Comparative study of the effects of pyridoxine, rifampin, and renal function on hematological adverse events induced by linezolid. Antimicrob Agents Chemother 2007;51:2559-2563.

15 Legout L, Valette M, Dezeque H, Nguyen S, Lemaire X, Loïez C, et al: Tolerability of prolonged linezolid therapy in bone and joint infection: protective effect of rifampicin on the occurrence of anaemia? J Antimicrob Chemother 2010;65:2224-2230. 